\title{
Spectroscopic and Photochemical Properties of some Annulated Boldine Derivatives
}

\author{
María E Hidalgo, ${ }^{* a}$ Myriam G. Alarcón, ${ }^{b}$ Juan R. Ojeda, ${ }^{b}$ Ernesto C. Fernández, ${ }^{b, t}$ \\ Eduardo M. Sobarzo-Sánchez ${ }^{c}$ and Julio R. De la Fuente ${ }^{d}$
}

${ }^{a}$ Facultad de Ciencias, Universidad de Valparaíso, Avenida Gran Bretaña 1111, Valparaíso, Chile

${ }^{b}$ Facultad de Farmacia, Universidad de Valparaíso, Avenida Gran Bretaña 1093, Valparaíso, Chile

'Departamento de Farmacia y Tecnologia Farmacéutica, Facultad de Farmacia, Universidad de Santiago

de Compostela, Praza Seminario de Estudos Galegos s/n, 15782 Santiago de Compostela, España

${ }^{d}$ Facultad de Ciencias Químicas y Farmacéuticas, Universidad de Chile, Vicuña Mackenna 20, Santiago, Chile

\begin{abstract}
O objetivo deste estudo foi determinar a influência dos grupos substituintes na fotoestabilidade de oito derivados de boldina, incluindo alguns derivados de oxazol e oxazinona, com o propósito de aumentar as propriedades de proteção solar previamente demonstradas para boldina. Tais derivados apresentaram bandas similares à boldina nos espectros de absorção e emissão. As propriedades espectroscópicas são dependentes do $\mathrm{pH}$. A fotoestabilidade dos derivados foi maior que a da boldina, em conformidade com o baixo valor obtido para o rendimento de fotoconsumo quântico. Os baixos valores de rendimento quântico de fluorescência observados para a boldina 1 e 4, tanto na sua forma de base como hidrocloreto, possibilitam postular que esses compostos são desativados por um mecanismo diferente ao da fluorescência, provavelmente devido ao efeito retirador de elétron do grupo NO para a boldina $\mathbf{1}$ e ao aumento da aromaticidade para a boldina $\mathbf{4}$.
\end{abstract}

The aim of this study was to determine the influence of the substituent groups on the photostability of eight boldine derivatives, including some oxazole and oxazinone derivatives, in order to increase the sunscreen protection properties previously demonstrated for boldine. Such derivatives showed bands similar to those of boldine in the absorption and emission spectrum. The spectroscopic properties are $\mathrm{pH}$ dependent. The photostability of the derivative compounds was higher than that of boldine, in accordance with the low value of the photoconsumption quantum yield determined. The low fluorescence quantum yield values observed for boldine $\mathbf{1}$ and $\mathbf{4}$ as both base and hydrochloride derivative compounds led us to postulate that these compounds are deactivated by a mechanism different to the fluorescence pathway, probably due to the electron-withdrawing inductive effect of $\mathrm{NO}$ for boldine $\mathbf{1}$, and to the increase of the aromatic framework for boldine $\mathbf{4}$.

Keywords: boldine, oxazol-oxazinone derivatives, photostability

\section{Introduction}

UV solar radiation has been implicated in cancer probably due to cellular damage that begins with proteins and DNA as the primary targets. This damage could be initiated by two mechanisms: (i) direct absorption of the incident light by the ground state or (ii) photosensitization, where the light is absorbed by an endogenous or exogenous photosensitizer that, excited to its triplet state, can be

\footnotetext{
*e-mail: maria.hidalgo@uv.cl
}

deactivated by electron transfer, hydrogen abstraction and/or the generation of singlet oxygen. ${ }^{1-3}$

With the purpose of reducing the effects of UV radiation, diverse molecules have been synthesized to act as radiation filters, diminishing the radiation dose (UVA/ UVB) received by the skin in topical applications. ${ }^{4-6}$ Recently, the increasing cosmetic use of solar filters has put in evidence the side effects associated with molecules used as photoprotectors. Such effects include photosensitivity reactions, such as allergies and phototoxicity, and constitute a strong limitation for the massive use of these filters; ${ }^{7}$ nevertheless, these limitations have encouraged the search 
for new molecules that have some basic characteristics: a high molar extinction coefficient in the UVA/UVB zone, photostability and innocuousness in topical use. In this context, natural products may be an important source for research into new active compounds. ${ }^{8}$

$(S)-(+)$-Boldine, ${ }^{9}$ the major alkaloid present in leaves and bark of the Chilean Boldo tree (Peumus boldus Molina, Monimiaceae), has been characterized in the past few years as an antioxidant that effectively protects different systems against free-radical-induced lipid peroxidation or enzyme inactivation. ${ }^{10}$ This activity presumably underlies the hepatoprotective and cytoprotective effects recently demonstrated for this alkaloid ${ }^{11}$ and may also be related to its antipyretic and anti-inflammatory behavior and to its protective effect in experimental colitis. ${ }^{12}$

Independently of these properties, boldine is a slightly selective R1A-adrenergic antagonist in vascular tissue and a nonselective D1- and D2-dopaminergic antagonist in the central nervous system. ${ }^{13}$ It therefore seemed interesting to study whether, by introducing substituents in the available boldine molecule, more favorable pharmacokinetics could be obtained, while maintaining or improving some of its useful pharmacological activities. ${ }^{14}$

Structure-antioxidative activity studies on boldine and related compounds suggest that both the phenol groups bonded to the aporphine ring system and the basic benzylic amine function contribute to these properties. ${ }^{15}$ Such structural features should be retained in boldine derivatives to be considered as potential antioxidants. On the other hand, there is presently no way of predicting the effects of derivatization of boldine upon its scantily known monoaminergic properties. ${ }^{16}$ Therefore, it seemed reasonable that variations on the boldine motif should aim for increased lipophilicity without affecting much the key phenolic and amine functional groups. One way of achieving this would be to replace the aromatic ring hydrogens with not very bulky substituents that would be expected to make a positive contribution to the overall lipophilicity. ${ }^{17}$

An important part of the deleterious effects of exposing skin to solar UV radiation is attributed to the generation of reactive oxygen species (i.e. singlet oxygen, superoxide and hydroxyl radicals). From a mechanistic perspective, the free radicals generated can cause cellular damage through oxidative modifications of lipids and/or membrane proteins (functional-structural), or through the alterations of nucleics acid. At the present time, a clear participation in the beginning and/or evolution of skin alterations, such as premature aging, dermatitis and skin cancer, is attributed to free radicals. As with the oxidative effects associated with UV radiation, the use of chemical agents such as boldine, that are able to scavenge free radicals ${ }^{18}$ and to interfere with oxidative processes, arises today as an interesting and promissory alternative of photoprotection.

The photoprotection capacity of boldine was evaluated before and after irradiation in a previous paper. The photostability and photoprotection factor of boldine and glaucine were compared, demonstrating that both are photoreactive under irradiation conditions. However, the photoproducts preserved the aporphine structure and showed a higher photoprotection factor (SPF). ${ }^{19}$ This is important for a future application of the alkaloid as a sunscreen.

All the synthesized boldine derivatives were capable of scavenging ROS (reactive oxygen species) generated by the hypoxanthine-xanthine oxidase system in a concentrationdependent manner. ${ }^{18}$ In this sense, phenanthrene alkaloids (boldine derivatives) may become promising candidates for the development of anti-inflammatory agents due to their strong ROS scavenging activity. In this paper, the influence of substituents groups and annelated systems such as oxazole and oxazinone rings against the photostability in eight boldine derivatives was evaluated.

\section{Experimental}

Boldine derivatives (1-4) (Figure 1) were synthesized and characterized by standard methods. ${ }^{14-17}$ Hydrochloride salts were prepared by dissolving the compounds in isopropanol and subsequently adding $\mathrm{HCl}$ to precipitate the hydrochloride with ethyl ether.

The reagents Brij 35 (Aldrich Laboratories, Milwaukee, WI, USA), dimethylsulfoxide and ethanol, methanol, tetrahydrofuran, acetonitrile (Merck, Santiago de Chile, Chile) were used. Distilled water adjusted to $\mathrm{pH} 3$ and 10 with $\mathrm{HCl}$ and $\mathrm{NaOH}$, respectively (Merck) was used.

\section{Absorption and emission spectra}

Absorption spectra were recorded in a Cecil C-550 spectrophotometer (Cambridge, England). Fluorescence spectra and fluorescence yields were measured in a Shimadzu RF-540 spectrofluorimeter (Kyoto, Japan).

\section{Fluorescence quantum yield}

Fluorescence were evaluated by comparing the fluorescence spectra of the compounds with that of anthracene in ethanol $\left(\phi_{\mathrm{Fl}}=0.27\right) .{ }^{20}$

\section{Solubility and pKa determination}

The solubility of the compounds was estimated from the absorbance of the saturated solution (after evaluating the 


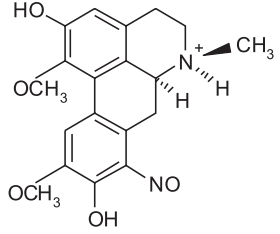

Bol 1 base<smiles>COc1cc2c(c(C(=O)O)c1O)-c1c(cc(O)c(O)c1O)CC[N+]2(C)C</smiles>

Bol 3 base<smiles>C[N+]1(C)CCc2cc(O)c(O)c3c2-c2cc([O-])c(O)c([N+](=O)[O-])c2C[C@@H]31</smiles>

Bol 1 salt

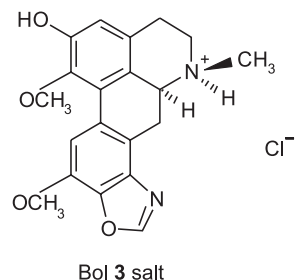

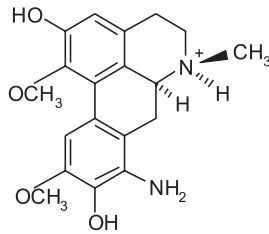

Bol 2 base

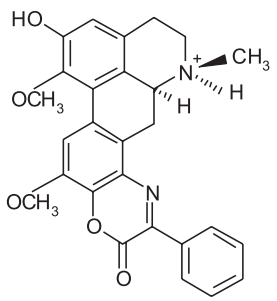

Bol 4 base

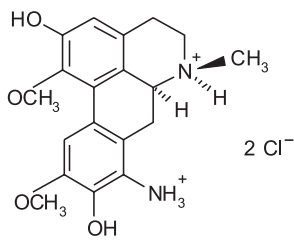

Bol 2 salt

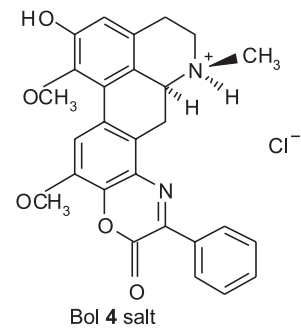

Figure 1. Boldine derivatives' structures.

extinction coefficient) using the break in absorbance versus the added concentration plot. The pKa values were obtained from plots of absorbance versus $\mathrm{pH}$ (titration curve).

\section{Photostability determinations}

Photolyses were performed in standard solutions of oxygen and nitrogen $\left(10^{-4} \mathrm{~mol} \mathrm{~L}^{-1}\right.$ derivatives 1-4) using a medium pressure mercury lamp (Hanovia Union, NJ, USA), monochromatic UVB light at $313 \mathrm{~nm}$ with $1460 \mu \mathrm{W} \mathrm{cm}^{-2}$ irradiance. The photodegradation was analyzed by high performance liquid chromatography (HPLC) using a Merck Hitachi Lachrom HPLC (Tokyo, Japan) (mobile phase ammonium phosphate $\mathrm{pH} 4.3$; acetonitrile-methanol; 45:12:1 (v/v/v); Merck RP 18e LiChroCART ${ }^{\circledR} 125-4$ column).

Due to the possible use of bases as sunscreen filters and their low solubility in water, photoconsumption quantum yields $\left(\phi_{c}\right)$ were evaluated in methanol solutions (derivatives 1-3, $2 \times 10^{-5} \mathrm{~mol} \mathrm{~L}^{-1}$ ) and in tetrahydrofuran

(THF, derivative $4,1 \times 10^{-5} \mathrm{~mol} \mathrm{~L}^{-1}$ ) and were irradiated during $2 \mathrm{~h}$ in a photochemical reactor (Rayonet Southern New England Ultraviolet Company, England, CT, USA) with an irradiance of $3100 \mu \mathrm{W} \mathrm{cm} \mathrm{cm}^{-2}$. The photoconsumption was evaluated from changes in the absorption spectra using the high performance thin layer chromatography (HPTLC) method (mobile phase chloroform-methanol-water; 65:40:2, v/v/v).

\section{Results and Discussion}

\section{Absorption spectra}

In Figure 2 the influence of $\mathrm{pH}$ on the absorption spectra of boldine derivatives (Bol 1 - Bol 4) base form was shown. In all spectra, there is a slight bathochromic shift in both bands at $\mathrm{pH} 3$ with respect to boldine in methanol, possibly due to the solvation of the non-bonding electrons from auxochrome groups, which would diminish the $\mathrm{n}$ orbital energy, therefore affecting the $\mathrm{n}-\pi^{*}$ transitions and producing the observed shift. ${ }^{21}$

At $\mathrm{pH} 10$, the first band shows a bathochromic shift only in derivatives in Bol $\mathbf{2}$ and Bol $\mathbf{4}$ bases and a hypsochromic shift in Bol $\mathbf{1}$ and $\mathbf{3}$ bases in the second band, presumably due to the stabilization of the $\pi^{*}$ excited state in the auxochrome groups by the solvent effect. ${ }^{21}$

\section{Fluorescence spectra, fluorescence quantum yield}

The fluorescence quantum yields (Table 1) of all compounds present low values and Bol $\mathbf{1}$ and Bol $\mathbf{4}$ bases are the lowest. This behavior may be due to the presence of paramagnetic substituents that could allow other deactivation paths such as intersystem crossing. ${ }^{21,22}$ The extending of the aromatic structure could enhance fluorescence due to the $\pi-\pi^{*}$ energy levels. The biphenyl system without conjugation (independent phenolic systems in boldine) is converted into a phenolic system conjugated with an oxazol or oxazinone in the derivates.

\section{pKa determination}

All boldine derivatives except Bol $\mathbf{2}$ base have two pKa values near 5 and 9 (Table 2). However, we must mention that the methodology shows limitations at certain $\mathrm{pH}$ values, where the absorbances may overlap. Nevertheless, values are in accordance with those reported previously by Shao-Wen et al., ${ }^{23}$ for molecules that have an aporphinic structure. From a structural point of view, a pKa around 4 or 5 corresponds to one of the hydroxyl groups, while a pKa between 8 and 9 would correspond to the amino group at $\mathrm{C} 6$ in ring $\mathrm{B}$. 

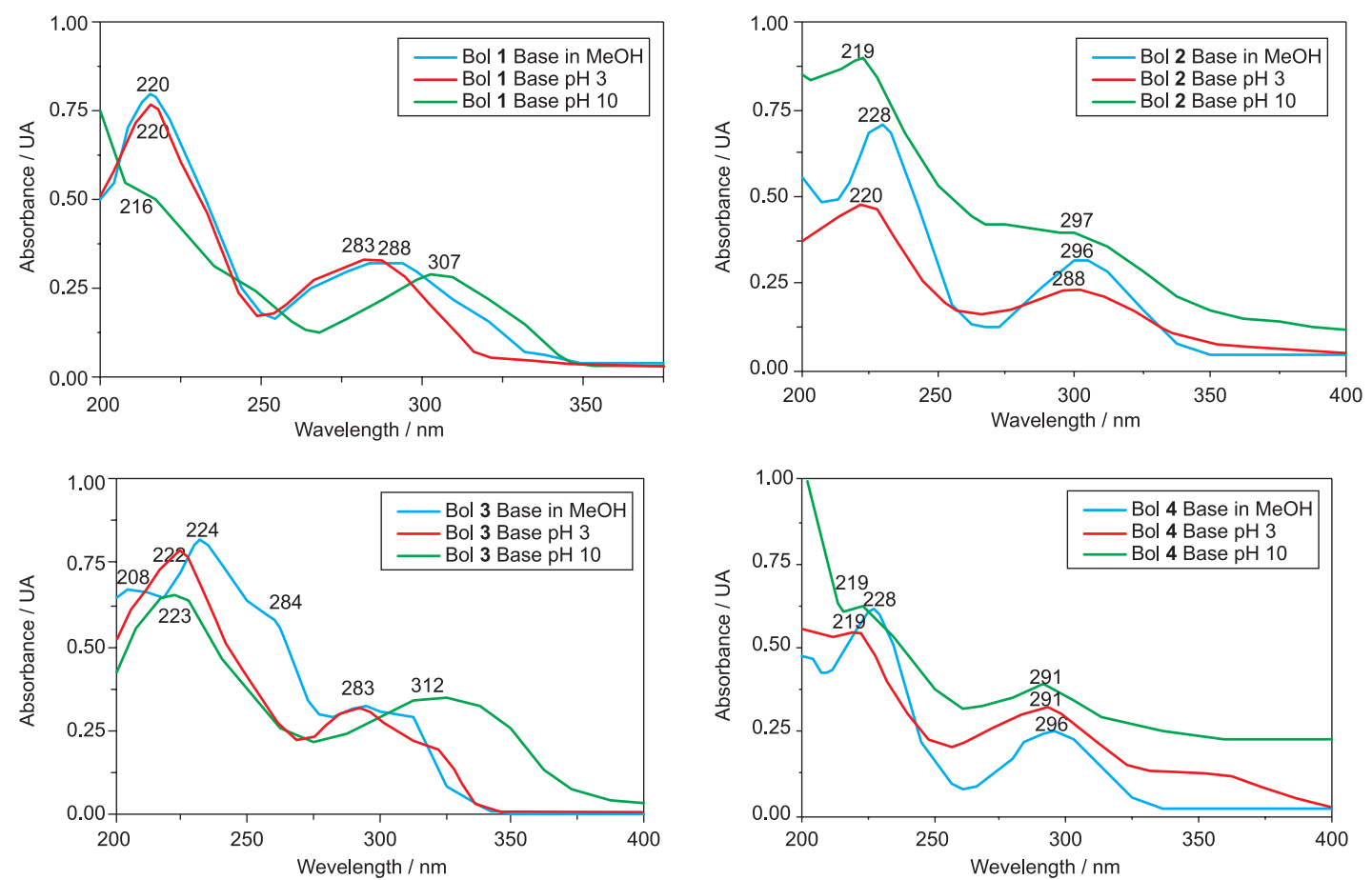

Figure 2. Absorption spectra at different $\mathrm{pH}$ values and in methanol.

Table 1. Fluorescence quantum yields

\begin{tabular}{|c|c|c|c|}
\hline \multirow{2}{*}{ Compound } & \multicolumn{2}{|c|}{$\lambda / \mathrm{nm}$} & \multirow{2}{*}{$\Phi_{f}$} \\
\hline & excitation & emission & \\
\hline Bol 1 Base/MeOH & 288 & $360-470$ & 0.0034 \\
\hline Bol 2 Base/MeOH & 296 & 414 & 0.2445 \\
\hline Bol 3 Base/MeOH & 284 & 359 & 0.2903 \\
\hline Bol 4 Base/MeOH & 296 & 412 & 0.0022 \\
\hline Bol 1 hydrochloride/MeOH & 282 & 406 & 0.0026 \\
\hline Bol 2 hydrochloride/MeOH & 297 & 418 & 0.3150 \\
\hline Bol 3 hydrochloride/MeOH & 286 & 408 & 0.3864 \\
\hline Bol 4 hydrochloride/MeOH & 294 & 410 & 0.0022 \\
\hline
\end{tabular}

Table 2. pKa values

\begin{tabular}{lcc}
\hline Compound & \multicolumn{2}{c}{ pka } \\
& $\lambda_{1}{ }^{*}$ & $\lambda_{2}{ }^{*}$ \\
\hline Boldine & $4.98-9.02$ & $4.98-9.00$ \\
Bol $\mathbf{1}$ Base & $4.97-8.97$ & $5.03-9.03$ \\
Bol $\mathbf{2}$ Base & $3.99-8.00$ & ---- \\
Bol $\mathbf{3}$ Base & $4.98-9.00$ & $5.01-9.00$ \\
Bol $\mathbf{4}$ Base & $4.49-8.50$ & $4.49-8.50$ \\
Bol $\mathbf{1}$ hydrochloride & $4.00-8.00$ & $5.00-7.98$ \\
Bol $\mathbf{2}$ hydrochloride & $4.00-8.03$ & $3.97-7.98$ \\
Bol $\mathbf{3}$ hydrochloride & $3.97-8.98$ & $3.99-8.00$ \\
Bol $\mathbf{4}$ hydrochloride & $3.99-8.98$ & $4.02-9.00$ \\
\hline
\end{tabular}

$* \lambda_{1}$ acid solution $(\mathrm{pH} 3)$ and $\lambda_{2}$ basic solution $(\mathrm{pH} 10)$.

\section{Photostability determinations}

The consumption percentages of boldine derivatives plotted as $\ln \left(\mathrm{C}_{0} / \mathrm{C}\right)$ (Figure 3) showed that, in the case of Bol 1 base, the initial concentration decreased 50\% when the solution was irradiated during approximately 40 min, reaching a maximum disappearance of around $90 \%$ at $80 \mathrm{~min}$ and then remaining constant at a maximum around $90 \%$, and then it remained constant (Figure 4). Consumption percentages of derivatives Bol $\mathbf{2}, \mathbf{3}$ and $\mathbf{4}$ bases were in the range from 10 to $30 \%$. At larger times, no variation in the concentration was observed.

By comparing the results obtained in the photostability kinetics of the different derivatives (Figure 3), the behavior of Bol 1 base is different to all other compounds studied, since it was first consumed and then reappeared. This behavior could be explained by the presence of the NO group in Bol 1, which could act as scavenge ${ }^{24,25}$ for radicals generated by irradiation, followed by release at longer times of photolysis; Bol $\mathbf{4}$ and Bol $\mathbf{3}$ bases had the lowest degree of decomposition, 16.5 and $15.9 \%$, respectively, after $2 \mathrm{~h}$ of irradiation (Figure 4) with a normal kinetic behavior. For instance, using these molecules the hydrochloride improved the solubility of boldine derivatives in most of the solvents used, producing no significant changes in the spectral properties, as observed in boldine. ${ }^{19}$

When comparing the photoconsumption quantum yield of derivatives with boldine (Table 3), the higher photostability of the substituted aporphinic structures is confirmed. Boldine 

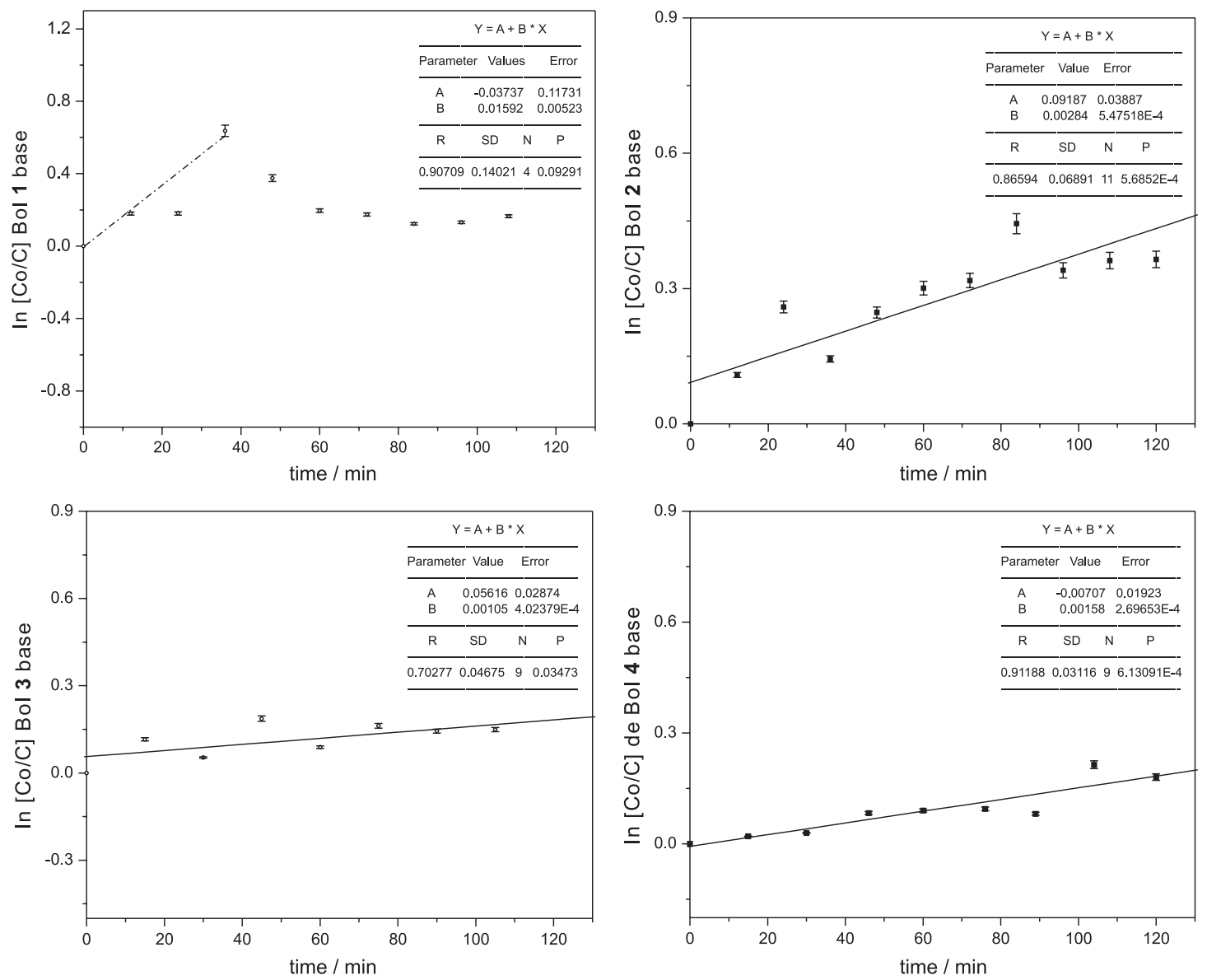

Figure 3. Photoconsumption kinetics determination.
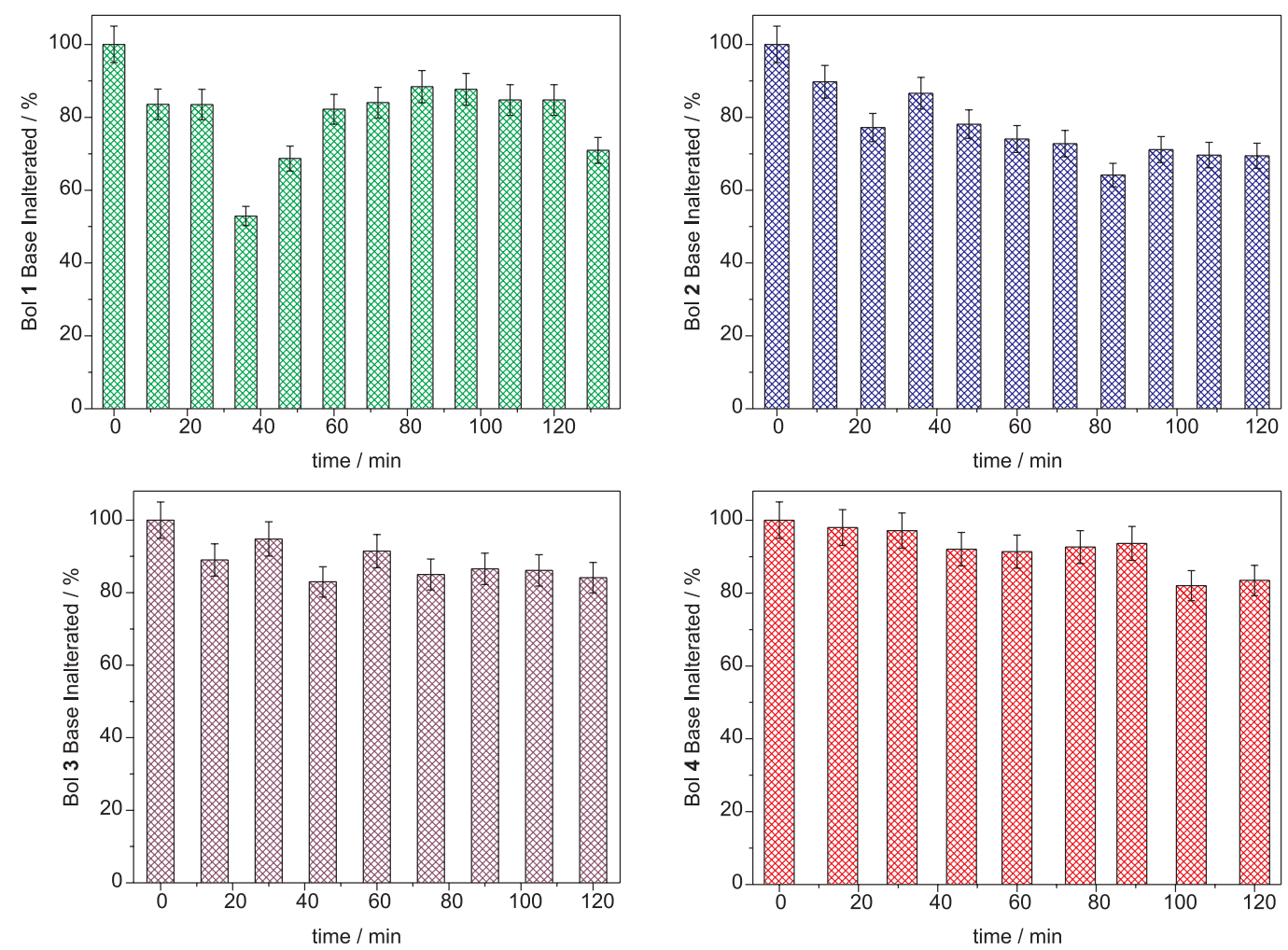

Figure 4. Consumption percentages of Bol 2, 3 and $\mathbf{4}$ bases. 
has a biphenyl system, which allows the existence of a double phenolic system which explains the stability of free radicals on the framework system. Furthermore, the nitroso and amine derivatives, as well as the incorporation of oxazole and oxazinone heterocycles, provided greater photostability, possibly due to electron-withdrawing and electron-releasing groups represented by nitroso-oxazinone and amine-oxazole that could stabilize possible radical intermediaries formed during irradiation.

Table 3. Photoconsumption quantum yields

\begin{tabular}{lcc}
\hline Compound & $\mathrm{k} \mathrm{air} / \mathrm{min}^{-1}$ & $\Phi_{\mathrm{c}}$ air $\left(10^{2}\right)$ \\
\hline Boldine & $0.043 \pm 0.006$ & 3.8 \\
Bol $\mathbf{1}$ base & $0.016 \pm 0.005$ & 2.5 \\
Bol $\mathbf{2}$ base & $0.003 \pm 0.001$ & 0.4 \\
Bol $\mathbf{3}$ base & $0.001 \pm 0.0004$ & 0.2 \\
Bol $\mathbf{4}$ base & $0.002 \pm 0.0003$ & 0.1 \\
\hline
\end{tabular}

\section{Conclusions}

All boldine base derivatives in this study showed lower photoconsumption quantum yields and photodecomposition rates than boldine. Thus, boldine derivatives bearing substituent groups and annelated heterocycles with the aporphinic structures have a higher photostability against UVB radiation.

The compounds derived from boldine bearing oxazole and oxazinone rings have promising photophysical and photochemical properties that would allow their use as possible sunscreens. Further studies of sun protection factor and phototoxicity are currently in progress.

\section{Acknowledgments}

E. S. thanks Dr. B. K. Cassels for his unconditional support and encouraging comments to continue this research.

\section{References}

1. Zanocco, A.; Lemp, E.; Günther, G.; J. Chem. Soc., Perkin Trans. 1997, 2, 1299.

2. Mothersill, C; Seymour, C. B.; EXS 2006, 96, 159.

3. Pattison, D. I.; Davies; M. J. In Cancer: Cell Structures, Carcinogens and Genomic Instability, Vol. 96, Bignold, L. P., ed., Birkhäuser: Basel, 2006.
4. Naylor, M. F.; Boyd, A.; Smith, D. W.; Cameron, G. S.; Hubbard, D.; Neldner, K. H.; Arch. Dermatol. 1995, 131, 170.

5. Darlington, S.; Williams, G.; Neale, R.; Frost, C.; Green, A.; Arch. Dermatol. 2003, 139, 451.

6. Lautenschlager, S.; Wulf, H. C.; Pittelkow, M. R; The Lancet 2007, 370, 528.

7. Shaath, N; Cosmet. Toilet 1987, 102, 21.

8. Liu, M. C.; Lin, C. T.; Shau, M. D.; Chen, Z. S.; Chen, M. T.; J. Food Drug Anal. 1996, 4, 243.

9. Speisky, H; Cassels, B. K.; Pharm. Res. 1994, $29,1$.

10. Speisky, H.; Cassels, B. K.; Lissi, E. A.; Videla, L. A.; Biochem. Pharmacol. 1991, 41, 1575.

11. Jiménez, I.; Speisky, H.; Phytother. Res. 2000, 14, 254.

12. Backhouse, N.; Delporte, C.; Givernau, M.; Cassels, B. K.; Valenzuela, A.; Speisky, H.; Inflamm. Res. 1994, 42, 114.

13. Loghin, F.; Chagraoui, A.; Asencio, M.; Comoy, E.; Speisky, H.; Cassels, B. K.; Protais, P.; Eur. J. Pharm. Sci. 2003, 18, 113.

14. Sobarzo-Sánchez, E.; Jullian, C.; Cassels, B. K.; Saitz-Barría, C.; Synth. Commun. 2002, 32, 3687.

15. Schmeda-Hirschmann, G.; Rodríguez, J. A.; Theoduloz, C.; Astudillo, S. L.; Feresin, G. E; Tapia, A.; Free Radic. Res. 2003, $37,447$.

16. Martínez, S.; Madrero, Y.; Elorriaga, M.; Noguera, M. A.; Cassels, B.; Sobarzo, E.; D’Ocon, P.; Ivorra, M. D.; Life Sci. 1999, 64, 1205.

17. Sobarzo-Sánchez, E.; Jullian, C.; Cassels, K. B.; Saitz, C.; Magn. Reson. Chem. 2001, 39, 361.

18. Milián, L.; Estellés, R.; Abarca, B.; Ballesteros, R.; Sanz, M. J.; Blázquez, M. A.; Chem. Pharm. Bull. 2004, 52, 696.

19. Hidalgo, M. E.; Farah, M.; Carrasco, L.; Fernández, E.; J. Photochem. Photobiol., B 2005, 80, 65.

20. Scaiano, J. C.; CRC Handbook of Organic Photochemistry, CRC Press: Boca Raton, Florida, 1989.

21. Rao, C. N.; Espectroscopia Ultravioleta y Visible, Editorial Alambra S.A.: Madrid, 1970.

22. Skoog, D. A,; Holler, F. J.; Nieman T. A.; Principios de Análisis Instrumental, $5^{\text {th }}$ ed., McGraw Hill/Interamericana de España S.A.: España, 2001.

23. Shao-Wen S.; Shoei-Sheng, L.; Hsi-Min, H.; J. Pharm. Biomed. Anal. 1996, 14, 1383.

24. Offer, T.; Samuni, A.; Free Radical Biol. Med. 2002, 32, 872.

25. Juergen, M.; Luttera, G.; Saraia, K.; Senn-Grossbergera, M.; Takahashic, N.; Bitu-Morenod, J.; Haberstrohb, J.; Beyersdorfa, F.; Eur J. Cardiothorac. Surg. 2001, 19, 321.

Submitted: October 14, 2008 Published online: September 23, 2010 